\title{
O LIMITE DA DÚVIDA: DELEUZE E O HOMEM DO SUBTERRÂNEO
}

\section{LA LIMITE DU DOUTE: DELEUZE ET L'HOMME DU SOUS-SOL}

Caio Whitaker Tosato ${ }^{1}$

Resumo: Pretendo apresentar um breve reflexão a partir de uma problemática anunciada por Gilles Deleuze no terceiro capítulo de Diferença e repetição (denominado $A$ imagem do pensamento), a qual evoca o problema do homem do subsolo enquanto um personagem conceitual. Fiódor Dostoiévski, em sua novela Memórias do subterrâneo, apresenta, a partir do protagonista, uma reflexão a respeito dos fundamentos da ação humana. Dessa forma, ele critica as noções de lei da natureza e lei moral através de um método de dúvidas. Pode-se dizer que os questionamentos do homem do subsolo levam a dúvida ao limite, provocando o desabamento dos pressupostos da explicação da ação humana (seja uma lei natural, seja uma lei moral).

Palavras-chave: Deleuze; Dostoievski; limite.

Résumé: Je prétends presenter un bref réflexion ]à partir de une problématique annoncé par Gilles Deleuze dans le troisième chapitre de Différance et répétition (appelé L'image de la pensée), lequelle évoque l'homme du sous-sol comme personnage conceptuel. Fiódor Dostoiévski, dans son roman Les Carnets du sous-sol présente, à partir du protagoniste, une réflexion sur les fondement de l'action humaine. De cette façon, il critique les notions de loi de la nature et de loi morale à travers d'une méthode de doute. On peut dire que les questionnement de l'homme du sous-sol portent le doute à la limite, provoquant l'effondrement des présupposés de l'explication de l'action humaine (soit une loi naturelle, soit une loi morale).

Mot clé: Deleuze; Dostoievski; limite.

O homem do subsolo de Fiódor Dostoiévski, na leitura de Deleuze, é o momento em que o método da dúvida e o personagem conceitual que o acompanha - o idiota - é levado a um limite tal que o questionamento é levado para o absurdo. Tal procedimento deve ser pensado como instaurador de uma lógica rigorosa. Dostoiévski, através das reflexões do homem do subsolo, traz uma potencialidade esquizofrênica para o método da dúvida, questionando, com isso, tanto a lei natural quanto a lei moral. Tal personagem abriria os caminhos, dessa forma, para pensar uma lógica e uma ontologia paradoxal, através do procedimento de levar o fundamento em direção a seu próprio desabamento. O que se faz através de um questionamento radical que ultrapassa tanto o senso comum quanto o bom senso.

Em Diferença e repetição (1968) Deleuze apresenta uma aporia a partir de um problema, trata-se de uma suspensão do pensamento a partir da tentativa empreendida pela filosofia moderna de escapar dos pressupostos do pensamento. Levando em conta uma passagem de $O$ que é filosofia (1995), onde o problema é retomado, pode-se pensar que o homem do subsolo radicaliza o método cartesiano da dúvida capaz de levar a lógica para o domínio do absurdo. $\mathrm{O}$ terceiro capítulo do livro de 1968 é o momento em que o autor elabora o problema dos pressupostos e da imagem do pensamento, o qual será retomado no livro de 1995. O filósofo defende que a filosofia moderna - cuja figura exemplar é Descartes - na tentativa de acabar com os pressupostos explícitos acaba recorrendo a pressupostos implícitos. Isso implica uma tentativa falha de começo filosófico, pois o verdadeiro começo se dá apenas quando os pressupostos se desabam. Durante a exposição do problema, o filósofo identifica no homem do

\footnotetext{
${ }^{1}$ UFSCar/CAPES.
} 
subsolo de Dostoiévski um personagem conceitual capaz de realizar o verdadeiro começo. Recorrerei a uma passagem da novela Memórias do subterrâneo de Dostoiévski, para mostrar que o literato russo realmente apresenta uma reflexão a propósito dos fundamentos.

A aporia deleuziana coloca o pensamento entre os dois tipos de pressupostos (explícitos e implícitos) e desenrola-se como um embate entre dois personagens conceituais - extraídos de um texto de René Descartes ${ }^{2}$. De um lado Epistemon, o pedante representante da escolástica, identificado como sábio público e dotado de saber excessivo da cultura de seu tempo; de outro lado, Eudoxo, o idiota representando Descartes, identificado como pensador privado e particular, dotado de boa vontade e pensamento natural. Segundo Deleuze, na segunda Meditação, o filósofo do século XVII não quer definir o homem como um animal racional (tal como o fazia Aristóteles), pois isso pressupõe as definições de "animal" e "racional" como já conhecidas. Tal seria a proposta de acabar com os pressupostos explícitos. Entretanto, na tentativa de acabar com tais pressupostos, os filósofos postulam como universalmente conhecido o que significa pensar (o pensamento como naturalmente reto). Ou seja, os pressupostos explícitos são substituídos por implícitos. Isso impede o verdadeiro começo, trazendo para o pensamento a matéria e o elemento necessários a instauração de uma imagem moral.

A imagem moral é responsável por determinar a condição de direito (quid juris) do pensamento verdadeiro. Estabelecer uma questão de direito significa sobretudo que de fato o pensamento não possui o verdadeiro. Isso implica a pressuposição do pensamento como naturalmente Bom (o bom senso enquanto medida dos seres) e como sendo o Mesmo (o senso comum como identidade do conceito). Nesse sentido pode-se dizer que a imagem moral depende da matéria da representação (o pensamento verdadeiro), cujo elemento é o acordo entre as faculdades (o exercício natural do pensamento). Para reencontrar o que o pensamento possui naturalmente de direito é necessário a aplicação de um método com a boa vontade do pensador. Assim, pode-se dissipar as forças estranhas que ameaçam subverter o pensamento. $\mathrm{O}$ quid juris instaurado pela imagem moral faz com que essas forças sejam reduzidas a meros fatos. Esse é o papel da figura do erro: retirar o direito dessas forças a inspirarem um verdadeiro problema transcendental. Isso porque elas trazem aquilo que difere infinitamente do modelo, uma diferença em estado selvagem.

Através da imagem do pensamento essas forças são aprisionadas. Deleuze vê na caverna de Platão aquilo que aprisiona essa diferença, através da instauração de um fundamento celeste (a Ideia) que julga os pretendentes. No tribunal platônico, a partir da instauração de um fundamento, realiza-se uma seleção na forma da distribuição de graus de participação (em relação a Ideia). Como ressalta David Lapoujade, em Deleuze e os movimentos aberrantes, o tribunal se organiza por uma tripartição: fundamento (o solo ou a Terra enquanto critério do julgamento); o princípio transcendental (quid juris enquanto distribuição do solo ou da Terra); e o princípio empírico (quid facti enquanto revindicação de um território - aquilo que cabe por direito ao fato).

A operação do tribunal se dá por um Juízo, o qual se articula através de duas operações: distribuição e hierarquização sedentárias. A distribuição sedentária se dá através da partilha da identidade do Mesmo (o senso comum), enquanto a hierarquização sedentária se dá através da medida dos pretendentes (bom senso). O valor do juízo é a Justiça, a justa medida, onde imperam os limites da lei (seja a lei moral ou a lei da natureza). Esse limite, Lapoujade o chama de relativo. A lei (ou o limite relativo) determina aquilo que pode ser repetido de direito do ponto de vista moral ou natural, considerando possível, através da figura do erro, vencer os

\footnotetext{
${ }^{2}$ É importante notar que as referências a Descartes são feitas única e exclusivamente a partir do que é apresentado por Deleuze. Mas é interessante notar que há a diferença do tratamento que o filósofo contemporâneo dá para o filósofo do século XVII na transição de Diferença e repetição para $O$ que é filosofia?, que não explorarei - ao menos não de forma explícita.
} 
problemas que escapam da verdade (a loucura, a besteira, a maldade). Os empreendimentos da lei impedem o verdadeiro começo filosófico o qual seria, de acordo com Deleuze, uma diferença primeira que coincide com a repetição.

Para pensar o verdadeiro começo Deleuze apresenta um contraponto a partir de um personagem conceitual: o homem do subsolo o qual, dotado de má vontade, não se deixa representar nem por pressupostos objetivos nem subjetivos. Com tal personagem Deleuze coloca em jogo um pensamento sem imagem através de uma distribuição nômade. Ele aparece como um contraponto a Descartes no seguinte trecho:

Mesmo que tenhamos de nos fazer de idiota, façamo-lo à maneira russa: um homem do subsolo, que nem se reconhece nos pressupostos subjetivos de um pensamento natural nem nos pressupostos objetivos de uma cultura de seu tempo e que não dispõe de compasso para traçar um círculo (DELEUZE, 2018, p. 181).

A novela Memórias do subterrâneo de Dostoiévski não é citada, mas a referência é clara. A exposição dos argumentos do protagonista será útil para ressaltar algumas conexões. Em $O$ que é filosofia o problema é retomado e esclarecido. Trata-se da capacidade do homem do subsolo levar a dúvida a um limite que a conduz até a loucura e ao absurdo, ultrapassando o bom senso e o senso comum. Contraria é a forma como Deleuze vê o método de Descartes, entendendo este como dependente do bom senso e do senso comum.

Considerando aquilo que era reduzido ao erro como um problema transcendental torna-se possível a instauração da legitimidade do absurdo na reflexão filosófica, o que permite Deleuze desenvolver uma lógica irracional e paradoxal. Eis o momento em que o fundamento desmorona nas retortas do irracional, arrastando-se para o sem-fundo. Esse é o momento no qual o "eu" é rompido e as faculdades são tomadas em seu uso transcendente, ou seja, levadas ao limite do que podem. O pensamento é levado até o impensável, a imaginação até o inimaginável, a percepção até o imperceptível, e assim por diante. Nota-se, portanto, um outro conceito de limite (daquilo que vai até o limite do que pode), denominado por Lapoujade limite absoluto.

A novela Memórias do subterrâneo de Dostoiévski, especialmente na primeira parte, trata das reflexões do chamado homem do subsolo ou do subterrâneo. Este personagem desenvolve um questionamento dos fundamentos da ação humana a partir de um contraponto entre duas figuras de homem. Trata-se da diferença entre o homem normal e o do subterrâneo, a qual se exprime em uma alegoria contada pelo personagem a respeito de um muro de pedra. Tal muro é a figura alegórica da lei. A grande questão é a diferença da atitude do homem natural em relação à do protagonista. Em relação ao primeiro o muro é tranquilizador, "do ponto de vista moral, encerra uma solução - algo definitivo” (DOSTOIÉVSKI, 2000, p. 22). Em relação ao segundo, por outro lado, é angustiante.

A diferença que se exprime na alegoria trata-se de duas atitudes contrapostas de cada uma dessas figuras quando tomadas por uma vontade de vingança. O chamado homem normal justifica seu espírito de vingança pela Justiça; esta serve fundamento de sua ação, fazendo com que tal homem fique em paz de espírito consigo mesmo, sem questionar suas próprias ações. Isso significa que ele tranquiliza-se na medida em que justifica seus atos de vingança. $\mathrm{O}$ homem do subterrâneo, ao contrário, não se contenta com tais justificativas, não aceita a Justiça enquanto fundamento da ação. Ele questiona as leis morais e até mesmo as leis naturais, pois ele não se contenta com as justificativas e, por isso, também não se contenta com as justificativas de sua ação. Por isso, mesmo as vezes tendo uma vontade de vingança maior do que a do homem normal, ele não consegue efetuar seu ato e, mesmo se conseguisse, não consideraria sua ação como justa. 
O protagonista explica o problema: quando tomado pelo desejo de vingar-se o homem normal age impetuosamente, "atira-se diretamente ao objetivo, como um touro enfurecido, de chifres abaixados, e somente um muro pode detê-lo" (DOSTOIÉVSKI, 2000, p. 21). Apesar de seu ímpeto, quando encontra o muro ele se tranquiliza, sente a sensação de ter encontrado "a causa primeira [de sua ação], o fundamento: a justiça" (DOSTOIÉVSKI, Fiódor, 2000, p. 30). Reconhece, assim, a Justiça como fundamento moral de sua vingança e tudo se encerra. Esse homem, apesar de ser capaz de se vingar e se defender (um homem de ação), é dotado de uma inata estupidez, se contenta e se acalma quando se depara com o muro.

O homem do subsolo, por outro lado, mesmo quando é tomado do sentimento de vingança (e este pode ser até maior do que o do outro homem), não consegue ver aí uma justiça, não se conforma com o muro. Para ele o muro é uma fonte de angústia. O protagonista declara ser apenas um camundongo, mas dotado de uma consciência hipertrofiada e, por isso, questiona tudo, leva a dúvida ao limite do absurdo ${ }^{3}$. Pode-se dizer, com Deleuze, que ele é o singular, dotado de má vontade e de má natureza. Sendo assim, o muro, enquanto aquilo que não pode ser transposto e nem pode ser negado, pode ser pensado como um limite relativo. $\mathrm{O}$ muro evoca o bom senso e o senso comum, enquanto as faculdades do juízo que constituem "a justa medida, a 'justiça' como valor do juízo" (DELEUZE, 2018, p. 60). Em suma, o muro é a lei. Mas a dúvida do homem do subsolo, conduzida ao limite, se recusa a acreditar nas leis da natureza e da matemática. Mesmo não tendo forças para derrubar o muro, o protagonista não se contenta:

O impossível quer dizer um muro de pedra? Mas que muro de pedra? Bem, naturalmente as leis da natureza, as conclusões das ciências naturais, a matemática.[...] Meu Deus, que tenho eu com as leis da natureza e com a aritmética, se, por algum motivo, não me agradam essas leis e o dois e dois são quatro? Está claro que não romperei esse muro com a testa, se realmente não tiver forças para fazê-lo, mas não me conformarei com ele unicamente pelo fato de ter pela frente um muro de pedra e de terem sido insuficientes as minhas forças. (DOSTOIÉVSKI, 2000, p. 24-25)

Frente a impossibilidade de se tranquilizar diante do muro, frente a impossibilidade de acreditar na Justiça como fundamento da moral, o homem do subsolo insiste no problema da causa primeira de sua ação, a ponto de desmanchar o fundamento da moral no absurdo:

Onde estão as minhas causas primeiras, em que me apoie? Onde estão os fundamentos? Onde irei buscá-los? Faço exercício mental e, por conseguinte, em mim, cada causa primeira arrasta imediatamente atrás de si outra, ainda anterior, e assim por diante, até o infinito. Tal é, de fato, a essência de toda consciência e do próprio ato de pensar. (DOSTOIÉVSKI, 2000, p. 29)

A essência do ato de pensar como uma regressão infinita evoca a lógica e a ontologia problemática que Deleuze desenvolve em Diferença e repetição. A condução do questionamento ao absurdo continua mesmo após essa passagem onde aparece a alegoria do muro de pedra (onde o problema dos fundamentos da ação humana é colocado). Uma outra problemática aparece, ainda na primeira parte da novela, a respeito da impossibilidade de determinar a vontade humana. Uma das imagens que Dostoiévski usa é a de um pedal de órgão, para dizer que a vontade não funciona a maneira de uma máquina, a qual responde ao pressionar

\footnotetext{
${ }^{3}$ Segundo Deleuze, a insistência dostoievskiana na dúvida é muito diferente do procedimento cartesiano; pois o questionamento não deseja mais o pensamento verdadeiro (através dos pressupostos implícitos), mas arrasta a dúvida ao limite, até o ponto que os fundamentos se desfazem.
} 
do pedal com o efeito esperado. $\mathrm{O}$ argumento do literato é que não se pode determinar nem mesmo que o homem age tendo em vista tomar vantagem das situações, pois o argumento cairia por terra se algum homem alguma vez agisse desejando algo que não lhe traz vantagem. A impossibilidade de determinação é afirmada mesmo no caso de que se conseguisse determinar a vontade matematicamente, pois nesse caso o homem enlouqueceria.

O fundamento da ação e da vontade é constantemente conduzido ao seu avesso, fazendo da imprevisibilidade um operador lógico para pensar as condições de impossibilidade, conduzindo o pensamento até o impensável. Conduzindo a dúvida ao absurdo, como coloca Deleuze em $O$ que é filosofia, Descartes, na Rússia, torna-se louco. Questionando os fundamentos, seja da lei moral ou natural, o método da dúvida é conduzido ao absurdo, trazendo algo do sem-fundo. No embate contra a determinação da lei, o desejo se depara com o indesejável e o pensamento é conduzido ao impensável. O muro treme, beirando a rachadura, na medida em que as faculdades são conduzidas até o limite do que podem.

\section{Referências}

DELEUZE, Gilles. Diferença e repetição. Tradução de Luiz B. L. Orlandi e Roberto Machado. Rio de Janeiro/São Paulo: Paz e Terra, 2018.

DELEUZE, Gilles; GUATTARI, Félix. O que é a filosofia? Tradução de Bento Prado Jr. e Alberto Alonso Muñoz. São Paulo: Editora 34, 1992.

DOSTOIÉVSKI, Fiódor. Memórias do subsolo. Tradução de Boris Schnaiderman. São Paulo: Editora 34, 2000.

LAPOUJADE, David. Deleuze, os movimentos aberrantes. Tradução de Laymert Garcia dos Santos. São Paulo: N-1 edições, 2017.

\section{Sobre o autor}

Caio Whitaker Tosato. Graduado em Ciências Sociais com ênfase em Antropologia pela UFSCar, mestrando em Filosofia pela mesma instituição, bolsista CAPES.

E-mail: caio.whitaker.tosato@gmail.com. 